\title{
Administration of dry powders during respiratory supports
}

\author{
Wei-Ren Ke ${ }^{1}$, Rachel Yoon Kyung Chang ${ }^{1}$, Philip Chi Lip Kwok ${ }^{1}$, Patricia Tang ${ }^{1}$, Lan Chen ${ }^{2}$, \\ Donghao Chen ${ }^{2}$, Hak-Kim Chan ${ }^{1}$
}

${ }^{1}$ Advanced Drug Delivery Group, School of Pharmacy, Faculty of Medicine and Health, University of Sydney, Sydney, New South Wales, Australia; ${ }^{2}$ Hangzhou Chance Pharmaceuticals, Hangzhou, China

Contributions: (I) Conception and design: WR Ke, P Tang; (II) Administrative support: None; (III) Provision of study materials or patients: WR Ke, P Tang; (IV) Collection and assembly of data: WR Ke, P Tang; (V) Data analysis and interpretation: All authors; (VI) Manuscript writing: All authors; (VII) Final approval of manuscript: All authors.

Correspondence to: Prof. Hak-Kim Chan. Advanced Drug Delivery Group, School of Pharmacy, Faculty of Medicine and Health, University of Sydney, Sydney, 2006, NSW, Australia. Email: kim.chan@sydney.edu.au.

\begin{abstract}
Inhaled drugs are routinely used for the treatment of respiratory-supported patients. To date, pressurized metered dose inhalers and nebulizers are the two platforms routinely employed in the clinical setting. The scarce utilization of the dry powder inhaler (DPI) platform is partly due to the lack of in vivo data that proves optimal delivery and drug efficacy are achievable. Additionally, fitting a DPI in-line to the respiratory circuit is not as straightforward as with the other aerosol delivery platforms. Importantly, there is a common misconception that the warm and humidified inspiratory air in respiratory supports, even for a short exposure, will deteriorate powder formulation compromising its delivery and efficacy. However, some recent studies have dispelled this myth, showing successful delivery of dry powders through the humidified circuit of respiratory supports. Compared with other aerosol delivery devices, the use of DPIs during respiratory supports possesses unique advantages such as rapid delivery and high dose. In this review, we presented in vitro studies showing various setups employing commercial DPIs and effects of ventilator parameters on the aerosol delivery. Inclusion of novel DPIs was also made to illustrate characteristics of an ideal inhaler that would give high lung dose with low powder deposition loss in tracheal tubes and respiratory circuits. Clinical trials are urgently needed to confirm the benefits of administration of dry powders in ventilated patients, thus enabling translation of powder delivery into practice.
\end{abstract}

Keywords: Dry powder inhaler (DPI); inhaled drug; respiratory support; mechanical ventilation; nasal high flow system

Submitted May 14, 2020. Accepted for publication Jul 19, 2020.

doi: $10.21037 / \mathrm{atm}-20-3946$

View this article at: http://dx.doi.org/10.21037/atm-20-3946

\section{Introduction}

Inhaled drug therapy is commonly employed in patients receiving respiratory supports (used here to describe nasal high flow system, noninvasive ventilation, invasive mechanical ventilation). Drugs can be delivered as aerosols using nebulizers, pressurized metered-dose inhalers (pMDIs) and dry powder inhalers (DPIs). DPIs provide several advantages over other delivery platforms, such as product stability, ease of handling, and flexible dosing (1). Unlike nebulizers and pMDIs, DPIs are breath-actuated devices that rely on the patient's inspiratory effort and the intrinsic DPI resistance for an effective aerosolization of the drug. The driving airflow through the inhaler is generated only when the inspiratory effort is strong enough to overcome the device resistance to produce a significant pressure drop $(2,3)$. However, the use of DPIs poses a challenge in patients receiving respiratory supports as they cannot breathe independently and provide sufficient inspiratory effort to actuate the inhaler.

This issue can be resolved by integrating the DPI in a circuit of respiratory support with an external power 
sources (e.g., respiratory supports, ventilation bag, additional pump). As the airflow is externally driven by a power source, the inhaler resistance becomes less critical. Furthermore, the positive pressure airflow from an external source can prevent the peripheral and small airways from collapsing during the inspiration (4). This facilitates deeper pulmonary aerosol penetration than that during negative pressure breathing. However, one should be cautious when actuating DPIs using mechanical ventilators as it may compromise the flow rate and inspiratory volume during volume- and pressure-controlled ventilations, respectively $(5,6)$. Therefore, the inspiratory airflow or volume need to be adjusted during dry powder administration to achieve effective aerosolization. Furthermore, to maximize drug delivery efficiency, synchronization of the aerosol device actuation and the inspiratory flow is recommended. In contrast to other devices, DPIs are actuated only when the airflow passes through the device. The use of an external air source to drive the DPI enables coordination of powder delivery with the inspiratory flow $(7,8)$. Thus, the dry powder and inspiratory airflow would always be delivered in synchrony.

Although DPIs possess several advantages, they have been under the misapprehension that dispersion performance will be adversely affected by humidified air (9). Thus, nebulizers and pMDIs are generally used for respiratory-supported patients. Some studies have dispelled this myth and successfully delivered dry powder through the humidified circuit of respiratory supports (10-12). In this article, we review different approaches for administering dry powders in the circuit of respiratory supports with a focus on issues related to aerosol performance. Factors that influence dry powder delivery during respiratory supports are also discussed.

\section{DPI-related factors influencing aerosol delivery}

\section{DPI characteristics}

DPIs utilize airflow to disperse powders into respirable aerosols. An effective aerosolization depends on the interactions between the device, inspiratory flow, and formulation (13-15). The design of DPIs considers both the device resistance and deagglomeration mechanism (16). Sufficient inspiratory effort is required to overcome the resistance and generate optimum flow turbulence for effective powder dispersion. In general, increasing the inspiratory flow rate improves dispersion by increasing turbulence $(17,18)$.

Another crucial factor affecting powder dispersion is the formulation. Particles are well-dispersed into inhalable aerosols when the airflow energy is strong enough to overcome inter-particle forces. Drug particles within a respirable-size range are usually cohesive, which hinders dispersibility (19). To reduce cohesion, one approach is to physically blend drugs with additional excipients, such as sugar derivatives and/or amino acids. Excipients with irregular surface structures and low surface energy can prevent drug particles from close interaction and improve dispersibility (20). Another approach is to use particle engineering techniques. Spray drying, for instance, is a technique for converting liquid feed into inhalable particles. The advantage of spray drying is the ability to modify particle characteristics, including particle size, morphology, crystallinity and surface roughness by manipulating multiple spray drying parameters as well as solvent system $(21,22)$.

Environmental factors, including relative humidity (RH) and temperature, have long been recognized to impact powder dispersibility as moisture and heat can influence inter-particle capillary force and powder triboelectrification (23-25). The extent of such impact depends on the physicochemical properties of drugs, such as hygroscopicity and deliquescence point $(26,27)$. The emitted doses of budesonide from Pulmicort ${ }^{\circledR}$ Turbuhaler $^{\mathrm{TM}}$ showed no significant changes when the $\mathrm{RH}$ of the dispersion air was increased from $40 \%$ to $90 \%$, while the fine particle fractions were only decreased by approximately 6\% (24). During momentarily exposures to humidity, the moisture adsorption on the powder was unlikely to have reached the equilibrium, so capillary forces between the particle would be minimal. In addition, the influence level of RH is dependent on the hygroscopicity of the powder $(28,29)$. Thus, using non-hygroscopic powder formulations is preferred for warm and humid environments.

\section{Advantages of DPIs usage during respiratory supports}

DPIs offer advantages for inhaled drug therapy, including improved portability, ease of use, and flexible dosing. In addition, dry powder formulations have higher chemical stability than solutions and do not require refrigeration. Therefore, DPI products are generally more common than nebules on the market. Ambulatory patients may use any inhalation product, but respiratory-supported patients have less choices because only nebulizers and pMDIs are currently used in respiratory supports. 


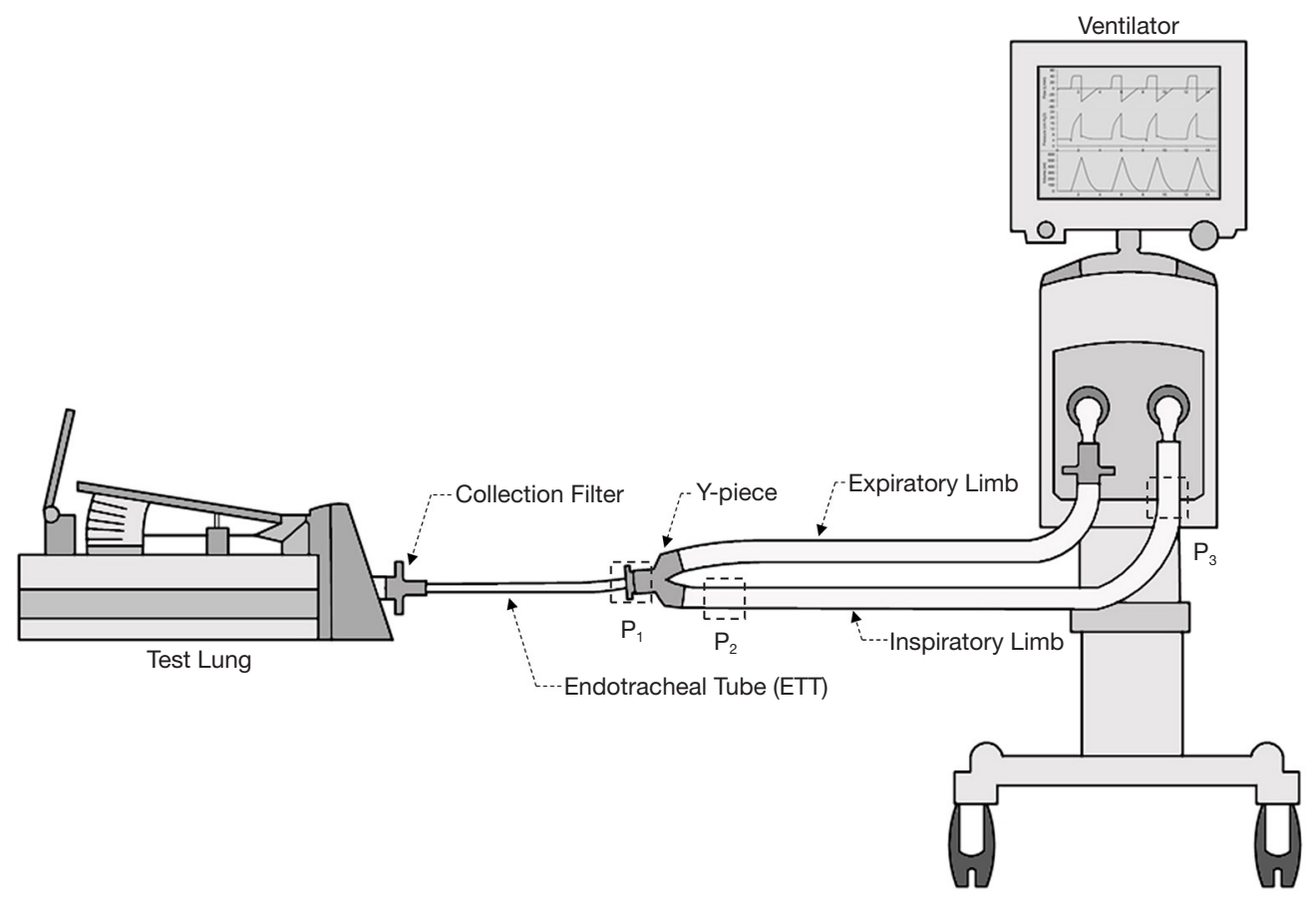

Figure 1 The in vitro adult mechanical ventilation model for the measurement of drug delivery from inhalers placed at various position in the circuit.

DPIs also possess an ability to administer a high dose of drugs to patients through the pulmonary route. Inhaled antibiotics, for instance, often require high doses (hundreds of $\mathrm{mg}$ ) to achieve the therapeutic effects, delivered by nebulizers and DPIs. Currently, only nebulizers are used to provide inhaled antibiotic during respiratory supports $(30,31)$ but it entails long administration times $(32,33)$. On the contrary, DPIs provide rapid administration duration and high drug delivery efficiency (34). Some high dose antibiotics (e.g., colistin and tobramycin) have been marketed as DPI products. For instance, Colobreathe ${ }^{\circledR}$ contains a dose of $125 \mathrm{mg}$ of colistimethate sodium dry powder and is administered using a Turbospin ${ }^{\circledR}$ inhaler. Schuster et al. demonstrated that no noticeable difference in therapeutic effect was found between Colobreathe ${ }^{\circledR}$ twice daily and nebulized tobramycin $(300 \mathrm{mg} / 5 \mathrm{~mL})$ twice daily (35). Besides commercial products, many other antibiotics have been formulated as dry powders for the treatment of tuberculosis, bronchiectasis and other respiratory diseases, and the developed formulation exhibited acceptable aerosol performance (36-38). These new formulations may be clinically tested and used in the future. DPI may be a suitable alternative for high-dose inhaled drugs in respiratory supports.

\section{Inline connection of a DPI in a respiratory circuit for non-invasive and invasive ventilation therapy}

There is no consensus yet on how to place the DPI in the ventilator circuit. The position of the inhaler in the ventilator circuit impacts aerosol delivery efficiency. Inhalers, including pMDI and soft mist inhaler (SMI), have been studied for the influence of the inhaler placement on delivered doses during mechanical ventilation $(39,40)$. Ke et al. compared three positions for both pMDI and SMI in a ventilator circuit with an adult lung model: (P1) proximal to the endotracheal tube (ETT), (P2) the inspiratory limb at $15 \mathrm{~cm}$ from the Y-piece, and (P3) $15 \mathrm{~cm}$ from the ventilator (Figure 1). The highest inhaled dose for both inhalers was achieved at (P2) $15 \mathrm{~cm}$ from the Y-piece and the lowest dose at (P3) $15 \mathrm{~cm}$ from the ventilator (41). The aerosol penetration is an inverse function of the length of tubing (42). Thus, drug aerosols tended to deposit more in the inspiratory limb when inhalers were placed farther away from the patient. However, placing the inhalers proximal to the ETT (P1) did not result in the highest inhaled doses. The reason could be that the emitted aerosols immediately encountered high airflow turbulence as they enter the narrow ETT resulting in high impaction loss $(39,41)$. 
Placing inhalers closer to the Y-piece in the inspiratory limb would provide longer time for the aerosols to adapt to the local fluid velocity, obtaining higher inhaled doses.

The optimal position of DPIs in mechanical ventilation circuit may differ to that from other inhalers. Most previous studies placed the DPIs proximal to the ETT when testing the delivery efficiencies during mechanical ventilation $(6,11,43,44)$. Apart from the high turbulence, DPIs at this position may lead to another issue in the clinical setting. If powders cannot be delivered completely at the first inspiration, residual powders in the DPI will be purged during expiration. These residual drug particles will be collected on the expiratory filter and further increase the patient's expiratory pressure. Placing the DPI between the ventilator and the heated humidifier could be beneficial to the powder dispersibility (45). Although emitted aerosols need to travel a long distance to reach the patient, the powder actuated at the position does not experience warm and humid airflow. Further studies are needed to evaluate the DPI delivery efficiency for different positions in the ventilator circuit.

In order to use commercial DPIs in both invasive and non-invasive ventilations, a delivery chamber has been employed to fully enclose a DPI (Figures 2,3). These two chambers have the same characteristics, i.e., it has (I) a single inlet to provide dispersion and delivery air; (II) an outlet connected indirectly or directly to a tracheal tube; and (III) an air-tight connection to avoid leakage that will reduce aerosol dispersion and delivery efficiency. In order to have an air-tight connection, a customized chamber needs to be constructed to match the size and shape of the DPI. The commercial DPI can be modified as long as the dispersion efficiency is maintained. For example, the mouthpiece of Pulmicort Turbuhaler ${ }^{\circledR}$ was removed and the outer covering was shortened to reduce the distance travelled by the powder emitted from the spiral de-aggregation channels and to increase the amount of delivered dose (43). The total dose delivered to the distal end of an ETT when the modified Turbuhaler ${ }^{\circledR}$ was connected to a ventilator was $20 \%$ of the nominal dose. The dead space of the chamber should be minimized to fully utilize the inlet air for aerosol dispersion. When the chamber is too large, the inlet air velocity will decrease due to the large cross-sectional area of the chamber. Additionally, the air will lose energy due to formation of eddies in the recirculation zone after the entrance of the chamber. This translates to lower force available to empty and deagglomerate the powder. Lightweight materials such as Perspex or Teflon are desirable to lessen the burden on the circuit and facilitate operation. Additionally, the use of cost-effective material will further add an advantage so that multiple chambers can be constructed to enable quick administration of multiple DPIs should the high dose delivery be required.

In vitro testing involving Aridol $^{\mathrm{TM}}$ capsules containing mannitol powder and Osmohaler ${ }^{\mathrm{TM}}$ (Pharmaxis Ltd, Sydney, Australia) was used to improve mucociliary clearance in intubated patients (Figure 2A). High doses of mannitol (above $120 \mathrm{mg}$ ) in lungs are required for this purpose. Four separate chambers and Osmohalers ${ }^{\mathrm{TM}}$ were used consecutively to introduce 4 capsules of $40 \mathrm{mg}$ or $80 \mathrm{mg}$ mannitol. The dose delivered to the distal end of tracheal tubes ranged from $48-64 \%$ and $55-62 \%$ of the total loaded dose of 160 and $320 \mathrm{mg}$, respectively. The same setup was also tested with an approved product Relenza ${ }^{\circledR}$ Diskhaler ${ }^{\circledR}$ (GlaxoSmithKline, Brentford, England, UK) containing $5 \mathrm{mg}$ zanamivir and $20 \mathrm{mg}$ lactose to treat influenza A and B (44). Emitted dose of $30 \%$ was achieved with Osmohaler ${ }^{\mathrm{TM}}$ compared to $18 \%$ with Diskhaler ${ }^{\circledR}$. The delivery system exhibited consistent mannitol and zanamivir dose delivery. This system offers a number of potential clinical advantages: (I) ability to rapidly administer high doses; (II) dose flexibility by varying the loaded amount and the number of capsules; (III) other DPIs can be simply inserted in line; (IV) consistent dosing to guarantee patient safety; and (V) the use of the delivery chamber may be less susceptible to contamination by the care provider or patient than standard jet nebulizers. It was noted in this work that powder may potentially build-up in the tracheal tube. This could be problematic for hydrophobic drugs because the accumulated powder can obstruct the tube and compromise patient safety. Adjustment in the bagging practice, such as additional compressions after powder delivery, may be required to clear the deposited powder inside. The disadvantage of this system is that it required disconnection of the tracheal tube from the respiratory circuit, which may impact patient's safety. Pathogens may potentially enter during disconnection and further cause lower respiratory tract infections $(48,49)$. The safety of patients suffering from hypoxemic respiratory failure is also compromised during disconnection (50). Therefore, it is undesirable to disconnect the patient from respiratory support. To address this issue, Feng et al. improved the setup by developing an in-line dry powder delivery system that does not require disconnection from the ventilator circuit (Figure 2B) (46). A separated line for Osmohaler ${ }^{\mathrm{TM}}$ enabled the continuous operation of the respiratory support while the inhaler was 
A

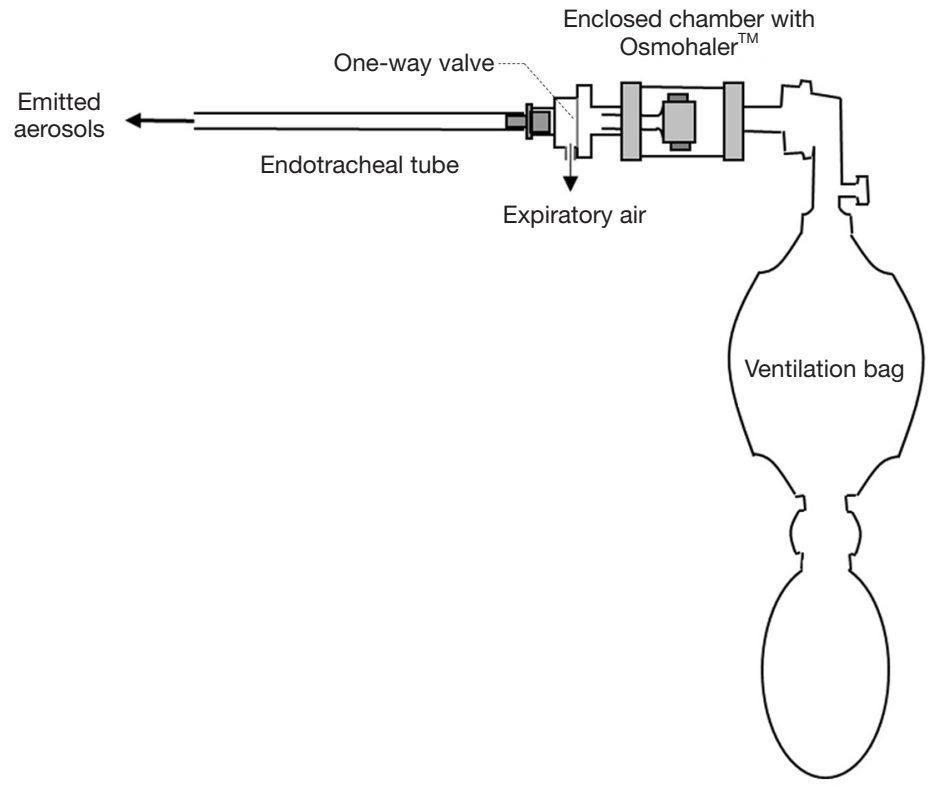

B

B Ventilator

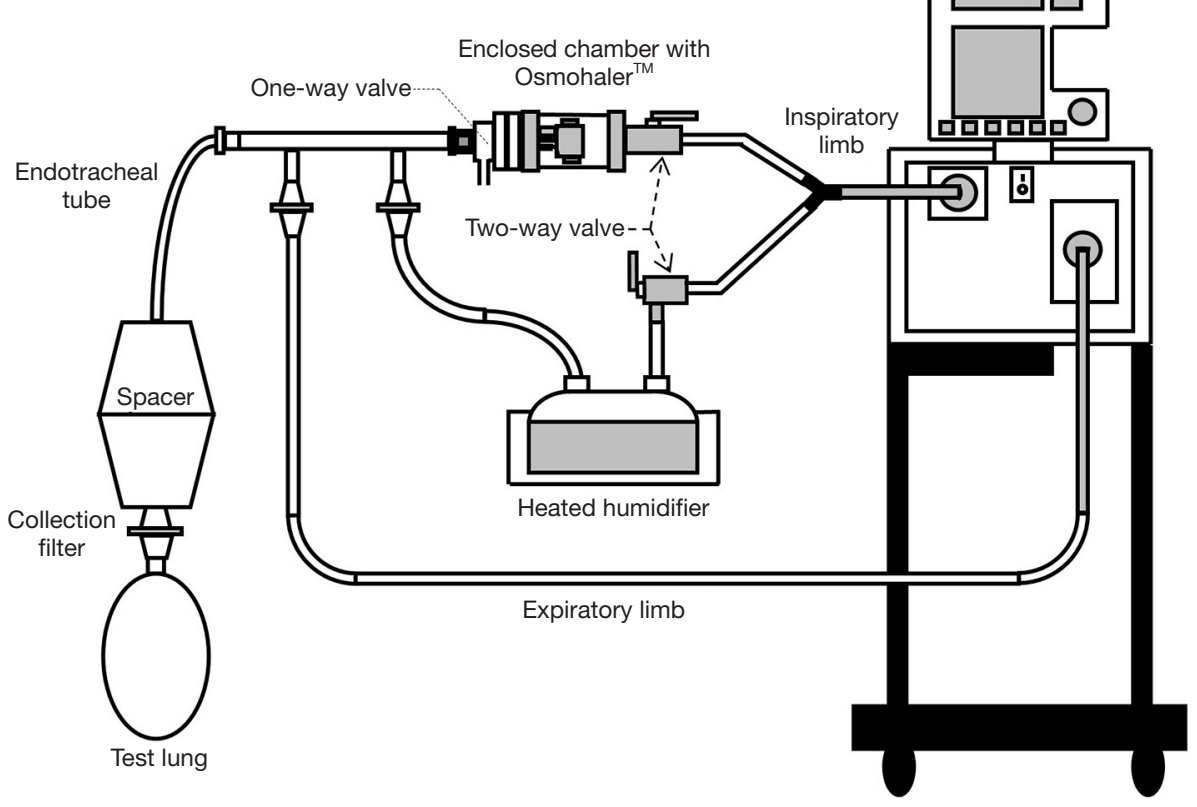

Figure 2 Osmohaler ${ }^{\mathrm{TM}}$ enclosed in a chamber connected inline between a tracheal tube and (A) a ventilation bag; (B) mechanical ventilator $(6,46)$.

reloaded. The downside of this setup was that it required manual coordination between the opening and closing of 2 two-way valves to direct the inspiratory airflow. The twoway valve that let air through the DPI must be opened just before the next inspiratory cycle to fully utilize the air source to disperse the powder. The other two-way valve needs to be closed immediately after that. It is possible to automate this action with an electronic three-way valve to replace manual coordination.

A potential issue with this delivery system is the blockage of the expiratory filter. When dry powder is introduced in mechanically ventilated patients, a small proportion of 

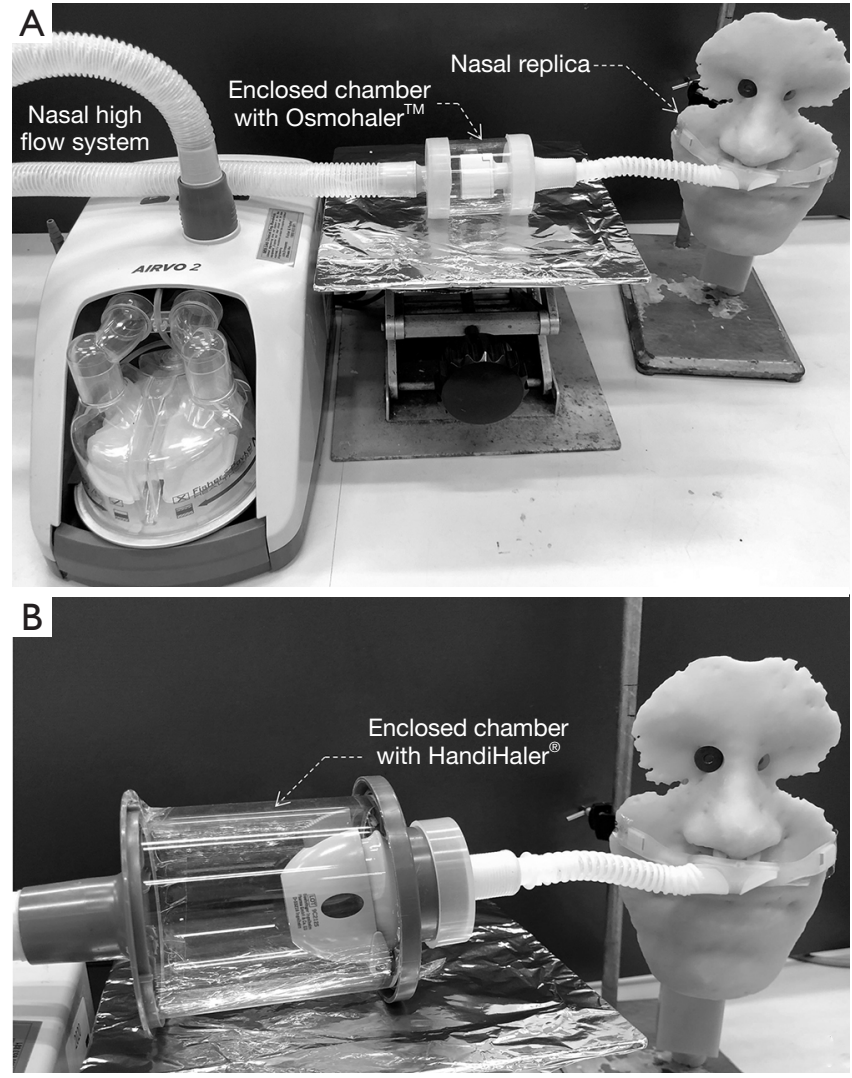

Figure 3 Commercial inhalers used for powder delivery through non-invasive nasal high flow (NHF) system. (A) Osmohaler ${ }^{\mathrm{TM}}$; (B) Handihaler ${ }^{\circledR}(12,47)$.

the powder may be expired and captured by the expiratory filter. Hence, it is imperative to change the expiratory filter when its resistance increases or every 24 hours after to avoid compromising patient safety (51). This issue has caused fatality. An intubated patient diagnosed with influenza-A pneumonia presented acute respiratory distress syndrome. Since Relenza ${ }^{\circledR}$ was only available as a dry powder, and the use of DPIs with a mechanical ventilator was limited at that time, the powder was reconstituted in saline and delivered with a nebulizer. Unfortunately, the solubilized lactose obstructed the expiratory filter and the patient died by asphyxiation (52). In vitro investigation confirmed that a significant increase of airway pressure was observed by sixth dose of zanamivir nebulization and acute ventilator occlusion took place by ninth nebulization.

The Perspex chamber enclosing the Osmohaler ${ }^{\mathrm{TM}}$ was further incorporated into a non-invasive nose-to-lung respiratory support (Figure 3A). The Osmohaler ${ }^{\mathrm{TM}}$ was connected to a clinically approved nasal high flow (NHF) system (AIRVO, Fisher Paykel, Healthcare, Auckland, New Zealand). The setup only achieved a lung dose of $8 \%$ of the loaded powder because of high powder deposition in the nose-mouth-throat (NMT) replica (12). Wallin et al. increased the lung dose by more than double by changing the inhaler to Handihaler ${ }^{\circledR}$ and adding L-leucine (co-spray dried with mannitol) to improve the powder dispersibility (Figure 3B) (47). The shortest connection tube $(13 \mathrm{~cm}$ in length) between the inhaler and nasal cannula was used in both systems to minimize powder loss. In practice, this means that a patient must be positioned very close to the unit which may restrict his/her movement.

\section{Effect of various parameters on aerosolization and delivery efficiency}

\section{Moisture}

For patients requiring long-term mechanical ventilation, the inspiratory air should be at body temperature and $100 \%$ $\mathrm{RH}$ to minimize water loss and consequently maintain cellular function, morphology and mucus transport at its optimum level (53). However, when powders come into contact with humidified air, the following will take place: (I) increase in particle size for hygroscopic powders; (II) increase of cohesion and adhesion forces that decrease dispersion (54); (III) crystallization of amorphous powders; and (VI) decrease of electrostatic charge. Therefore, it is imperative to minimize the moisture exposure in order to maintain the optimal aerosol performance. The lung dose of nano-sized budesonide particles showed a $23 \%$ reduction at $81 \% \mathrm{RH}$ compared to $51 \% \mathrm{RH}$ when dispersed in a mechanical ventilator circuit (11). Spray dried mannitol, on the other hand, was not affected by humidity when dispersed using a nasal high flow system because it is nonhygroscopic (12).

To avoid the contact between powder and moisture, the inspiratory line from a mechanical ventilator was split into two branches. The first branch passed through a heated humidifier to provide warm air at $100 \% \mathrm{RH}$ for patients during tidal breathing. The second branch bypassed the humidifier and provided drier air to disperse the powder out of the inhaler, and to push through one way valve, tracheal tube and finally reached the patient (Figure 2B) (46). A one-way valve was used to direct the expiratory air and not re-enter the inhaler (Figure 2). Behara et al. used a novel inhaler, actuated by a ventilation bag, to administer powders 


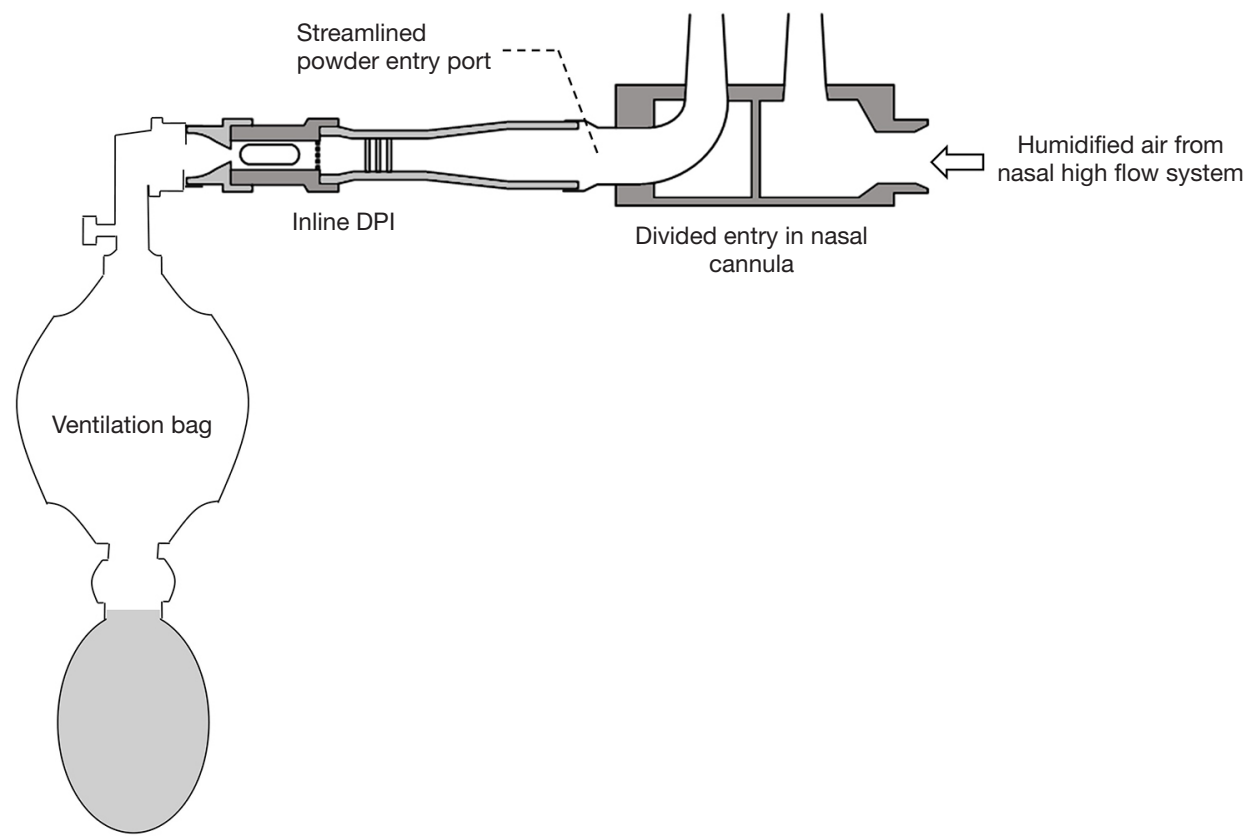

Figure 4 A novel DPI fitted directly into a NHF respiratory circuit connected between a ventilation bag and a nasal cannula (55).

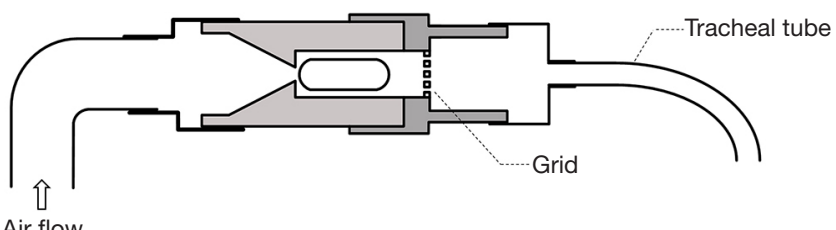

Air flow

Figure 5 A novel DPI that can be fitted directly into a respiratory circuit connected between a mechanical ventilator and a tracheal tube (11).

through one side of the nasal cannula (Figure 4) (55). Humidified air from the NHF system entered the other side of the nasal cannula in order to minimize powder exposure to moisture. There are additional benefits with a separate line for powder administration. Disconnection of the circuit is not required, so the respiratory support can operate continuously during powder reloading. Less powders are retained in dry tubing than wet ones so there is less powder retained in the circuit if the powder is dispersed into the separate, dry tubing.

Figure 4 shows a redesigned left nasal cannula by streamlining the powder entry port to reduce deposition. A streamlined customized Y-connector in a mechanical ventilator circuit has also been reported to reduce powder deposition by $37 \%$ and increased lung deposition by
$44 \%$ (56). Sites with sharp direction changes in the respiratory circuit should therefore be eliminated to achieve maximum powder delivery.

Everard et al. (43) and Pornputtapitak et al. (11) did not use a separate line for the DPI in their in vitro works. They positioned the DPI immediately before the tracheal tube to reduce powder deposition in the respiratory circuit (Figure 5). However, in a real clinical setting, the powder and DPI will be continuously exposed to moisture from inhalation and exhalation air if they are left in the line. As a result, the powder may undergo undesired physicochemical changes that reduce its stability and dispersibility. A wet inhaler may also retain more powder, thereby reducing the emitted dose. To minimize the duration of moisture exposure, DPI should be inserted in-line just before the powder administration and removed immediately afterwards. This action requires disconnecting patients from the respiratory support which, as mentioned before, is a health risk.

To mimic humid conditions, many reported in vitro tests were conducted with the 'rain-down' condition in the tracheal tube where the tube was wetted up to the point where water droplets started to coalesce and flowout $(6,44,46)$. However, Ryan et al. showed that there was minimal cooling as the expiratory air travelled out from the body until it was exposed to the cooler ambient 
condition (53). Consequently, moisture condensation on the interior surface of tracheal tube in this region would be minimal. Based on this fact, it allows in vitro testing to be done with a non 'rain-down' condition.

\section{Dispersion peak flow and acceleration rate}

High turbulence inside a DPI is required for optimum aerosolization. The turbulence is achieved from a combination of inlet air flowrate and deagglomeration mechanism inside the DPI. High resistance inhalers produce the required turbulence level at lower air flowrates than low resistance inhalers. Air flowrate can have two opposing effects on the emitted dose. On the one hand, higher turbulence can increase impaction loss in the respiratory connecting tubes, tracheal tubes, extrathoracic regions (for nose-to-lung respiratory support), and the oropharynx (for non-invasive therapy), resulting in a lower emitted dose. On the other hand, higher flowrates exert more force in pushing the powder out of the tubes, resulting in a higher emitted dose. The acceleration rate to reach peak flow also affects powder emptying and deagglomeration efficiency. A faster acceleration rate will empty the powder quicker. However, depending on the formulation and deagglomeration mechanism, the fast emptying rate may improve or worsen powder dispersion. If the powder is easy to disperse, then a fast emptying rate will be sufficient to deagglomerate it. However, for more cohesive powders a longer emptying rate will lengthen powder exposure to the turbulence and deagglomerate better. A square airflow waveform, available in a mechanical ventilator, enables the fastest acceleration rate compared to ramp and sinusoidal waveforms. Optimum aerosolization will depend on combinations of many different factors such as the degree of turbulence, duration of exposure to turbulence, formulation characteristics and dispersion mechanism. The effects of peak flow and acceleration on different powders and delivery systems are discussed below.

A square airflow waveform was found to significantly improve the emitted dose at the distal end of the tracheal tube (Figure 2B) (46). The emitted dose was reduced by $20 \%$ when a ramp waveform was used instead. With the square wave, the mannitol powder showed maximum deagglomeration at a low peak flowrate of $40 \mathrm{~L} / \mathrm{min}$ and therefore the fine particle fraction (FPF) remained the same at higher flowrates. When the flowrate was increased from 40 to $60 \mathrm{~L} / \mathrm{min}$, more powder came out from the inhaler but was trapped inside the endotracheal tube. This caused the emitted dose to be unchanged.

A standard adult manual ventilation bag was used to provide positive air pressure to disperse spray dried mannitol powder out of the Osmohaler ${ }^{\mathrm{TM}}$ (Figure 2A) (6). The peak flowrate and acceleration were varied by compressing the ventilation bag at different speeds and power. Higher peak flowrate and faster acceleration did not change the FPF significantly (Figure 6). This was because the powder was sufficiently dispersed at the lowest peak flow and acceleration. Higher peak flowrate did not reduce the emitted dose, implying that higher turbulence did not cause more deposition in the tube. In fact, the emitted dose obtained at $133 \mathrm{~L} / \mathrm{min}$ was higher than at $87 \mathrm{~L} / \mathrm{min}$ (Figure 6A) indicating that more powder could be pushed out of the tube with stronger force. Similar observation was reported when the formulation was changed from mannitol to a physically blended formulation of zanamivir and lactose (44).

Okuda $e t a l$. used the same spray dried mannitol powder for nose-to-lung delivery (Figure $3 A$ ) and similarly found that increasing the dispersion flow (30 to $60 \mathrm{~L} / \mathrm{min}$ ) did not change the FPF (12). However, it resulted in $20 \%$ more extrathoracic deposition (NMT replica) and 20\% decrease in the emitted dose. A much higher FPF (21\% to $32 \%$, Figure 7) was successfully achieved when L-leucine was added to the formulation and a Handihaler ${ }^{\circledR}$ was used (47). Deposition in the nasal cannula and connection tube increased ( $24 \%$ to $42 \%$ ) when dispersion flowrate (DFR) was increased from 20 to $30 \mathrm{~L} / \mathrm{min}$. The increase was due to the high turbulence and $90^{\circ}$ flow direction change when the aerosol entered the nasal prongs. Figure 7 also shows that the deposition inside the NMT replica was independent of DFR but generally increased with the inspiratory flowrate (IFR) which was attributed to enhanced impaction and turbulent deposition. Okuda et al. showed dependency of replica deposition with DFR due to the larger particle size because of the less dispersible pure mannitol powder (12).

\section{Improving delivery by decreasing dispersion airflow}

DPIs are supposed to achieve optimum aerosolization at a flowrate that can be generated by patients comfortably at a $4 \mathrm{kPa}$ drop across the inhaler. Among the marketed DPIs, Handihaler $^{\circledR}$ has the highest resistance $\left(0.0504 \mathrm{kPa}^{1 / 2} / \mathrm{L} \mathrm{min}^{-1}\right)$ and the flowrate that can be comfortably achieved is $40 \mathrm{~L} / \mathrm{min}$ (3). To minimize the impaction loss downstream of a DPI when it is connected in-line in a respiratory circuit, many novel DPIs have been developed that use a low peak flowrate ( $<40 \mathrm{~L} / \mathrm{min}$ ). In this section, we will briefly report these DPIs because they have the potential to improve the powder delivery 

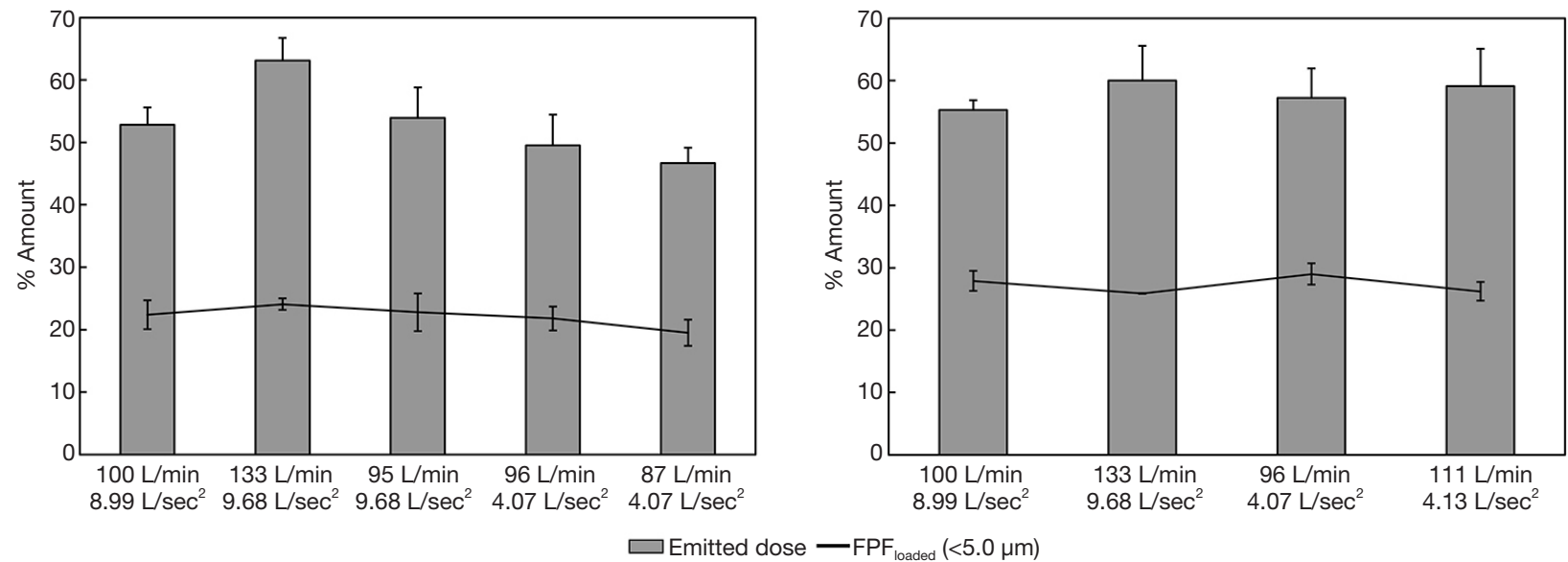

Figure 6 Effect of peak flowrate and acceleration on the emitted dose and fine particle fraction from an $8.5 \mathrm{~mm}$ endotracheal tube when a mannitol powder was dispersed from an Osmohaler ${ }^{\mathrm{TM}}$ with loaded dose of (A) $160 \mathrm{mg}$; and (B) $320 \mathrm{mg}$ (6).

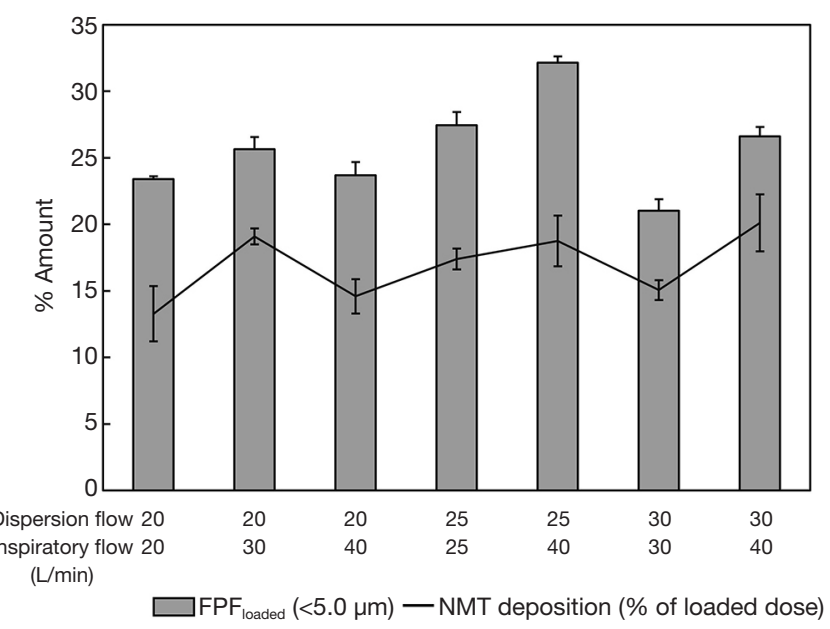

Figure 7 Fine particle fraction $(<5 \mu \mathrm{m})$ and nose-mouth-throat deposition with respect to loaded dose of $40 \mathrm{mg}$ spray dried mannitol-leucine powder when dispersed from a Handihaler ${ }^{\circledR}$ connected to nasal cannula (52).

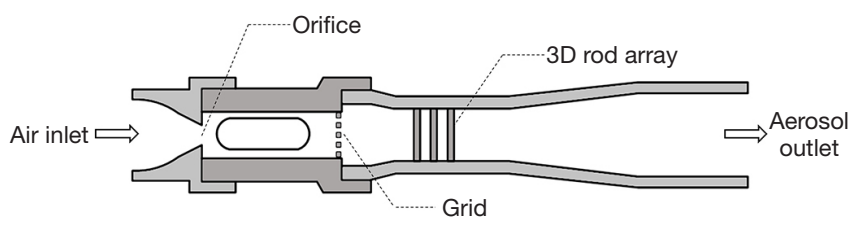

Figure 8 A novel DPI that can be fitted directly into a respiratory circuit (55). to patients on respiratory support. However, it is important to note that the main concern with employing a non-commercial inhaler is the off-label drug use (OLDU) application. Capsules that are originally approved for a particular DPI are now utilized with a different inhaler. Although OLDU may be clinically appropriate, its use involves safety, legal and ethical issues $(57,58)$. This option should be adopted only when there is a strong evidence supporting the OLDU of a product. Furthermore, most of these inhalers are limited to capsulebased formulations and therefore unsuitable for blister- or reservoir-based products.

A customized DPI which requires low flowrates (15 to $27 \mathrm{~L} / \mathrm{min}$ ), actuated by an adult ventilation bag, has exhibited efficient powder deagglomeration for nose-to-lung delivery (Figure 8) (55). Air entered the DPI through an orifice and emptied the powder from a capsule. Emitted aerosols experienced further deagglomeration when passing through a 3D arrangement of rod array before leaving the DPI. The DPI was incorporated into a NHF system (Figure 4) (55) and a facemask to introduce aerosols to the left nostrils during noninvasive positive pressure ventilation (NPPV) from a mechanical ventilator (10). An in vitro experiment combined with a well-developed and validated CFD model showed lung doses as high as $75 \%$ and $89 \%$ with this DPI.

It is important to know the resistance of a DPI before incorporating the device in the inspiratory line of the respiratory circuit. A high resistance inhaler will increase the workload of the respiratory circuit compared to the one with lower resistance. The higher the inhaler resistance, the harder the ventilator needs to work to maintain the same inspiratory flowrate. Feng et al. reported a drop in 


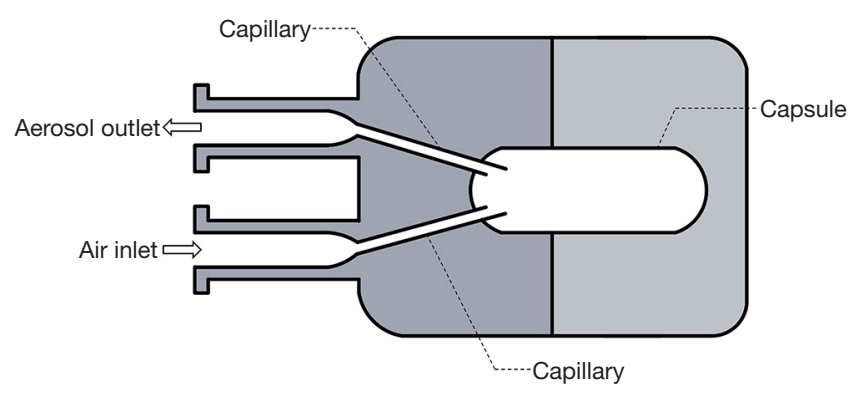

Figure 9 A novel DPI that can be fitted directly into a respiratory circuit (7).

inspiratory air flowrate from a mechanical ventilator by $20 \mathrm{~L} / \mathrm{min}$ when an Osmohaler ${ }^{\mathrm{TM}}$, a low resistance device $\left(0.0216 \mathrm{kPa}^{1 / 2} / \mathrm{L} \mathrm{min}{ }^{-1}\right)$, was inserted in-line (46). The novel DPI depicted in Figure 5 has a higher resistance $\left(0.0514 \mathrm{kPa}^{1 / 2} / \mathrm{L} \mathrm{min}^{-1}\right)$ than Osmohaler ${ }^{\mathrm{TM}}$. The inspiratory airflow from the mechanical ventilator would likely be reduced more than $20 \mathrm{~L} / \mathrm{min}$. Therefore, it is important for patient safety to confirm that a respiratory system can overcome the inhaler resistance. For high resistance inhalers, it is better to have a separate source of dispersion air (i.e., an active inhaler) to reduce the workload of the respiratory system. The DPI can then be incorporated into the respiratory circuit through a T- or Y-connector on the ventilator's inspiratory arm that is commonly used with pressurized metered dose inhaler or nebulizer in mechanical ventilators.

The novel DPI shown in Figure 9 has a separate source of dispersion air supplied by a syringe. This device was demonstrated to efficiently deagglomerate $10 \mathrm{mg}$ of albuterol sulphate-mannitol-L-leucine-poloxamer 188 powder formulation ( $85 \%$ lung dose) by using only $10 \mathrm{~mL}$ of air per actuation at $3 \mathrm{~L} / \mathrm{min}$ to target late preterm infants (7). As the DPI only requires a small volume of air at a relatively low flowrate to sufficiently aerosolize the formulation from a capsule, impaction loss in the tubing is expected to be minimal. This was confirmed by the emitted dose as high as $95 \%$. By synchronizing syringe actuation with the inspiratory cycle, the generated aerosols can be entrained by the inspiratory air and delivered to the patients.

The concept of an active inhaler where powder generation is initiated by an internal energy source can avoid adding unnecessary workload into the circuit and the dependency of aerosolization to the inlet airflow. A piezoelectric polymer was connected to a signal generator to vibrate a powder bed to generate the aerosols (59).
While the Spiros ${ }^{\circledR}$ device uses battery-operated rotating blades, and the Exubera ${ }^{\circledR}$ uses compressed air through a well-designed flow channel, other active devices utilize ultrasound inducing technique for deaggregation (60). An active DPI with internal pressure pulses introduced $14 \mathrm{~mL}$ of air, with each pulse continuously drawing recombinant surfactant protein-C spray dried powder from a container and aerosolize it into a spacer (Figure 10) (45). Continuous powder generation is possible with this DPI. Powder concentration can be adjusted by varying the frequency of the pulses and auxiliary air flowrate. Incorporating active DPIs into a mechanical ventilator will be attractive for clinical use. To date, there is no active DPI approved for human use partly due to their complexity and cost.

These active DPIs will be suitable for patients with limited inspiratory capacity or those with compromised lung functions, such as infants, neonatal and COPD patients. Neonates with lung diseases have volumetric breathing rate less than $1 \mathrm{~L} / \mathrm{min}$, tidal volumes of $5.15 \pm 1.35 \mathrm{~mL} / \mathrm{kg}$ and high breathing rates of $55.4 \pm 14.2$ per minute (61). The small lung volume and short breathing period pose a great challenge for efficient aerosol delivery as low inspiratory volumes needs to be employed. However, the low volume may not sufficiently disperse the powders from most commercial DPIs and carry the aerosols through the respiratory circuit to reach the patients.

To ensure that powder aerosols can reach the airways, a tidal volume of the respiratory support equipment must be larger than the dead volume between the DPI and the distal end of the tracheal tube (Figure 2B). Feng et al. set a large tidal volume of $950 \mathrm{~mL}$ in the mechanical ventilator to successfully carry the aerosols to the distal end of the endotracheal tube. It was acknowledged that $950 \mathrm{~mL}$ volume can cause volutrauma (62) so this volume was strictly used during dry powder administration only. This system will not be suitable for patients with limited lung capacity. Therefore, there is an urgent need to have regulatory approved active DPIs which can achieve excellent aerosolization with small air volume because they would be suitable for these patients.

\section{Tracheal tubes}

Tracheal tubes, which refer to endotracheal and tracheostomy tubes, of varying diameters are commonly used to support respiratory therapy for patients who cannot breathe on their own. Tubes with internal diameters of 5.0 to $9.5 \mathrm{~mm}$, and 3 to $4 \mathrm{~mm}$ are available for adults and infants, respectively. Tracheal tubes are the main barrier for optimal aerosol 


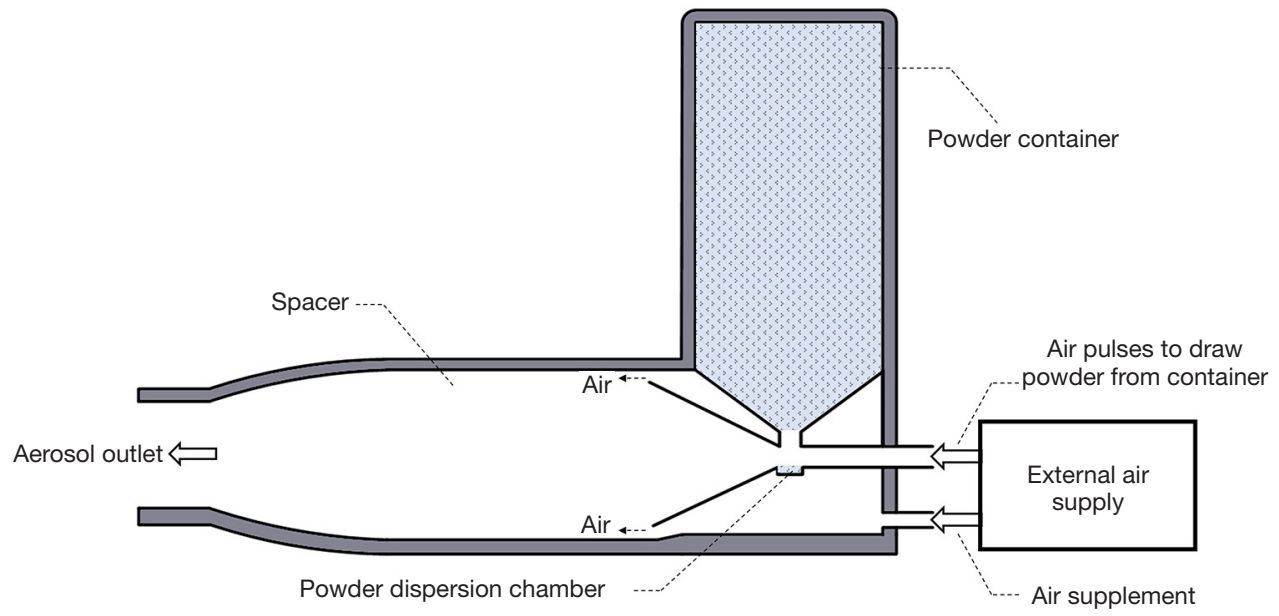

Figure 10 Active DPI with a built-in compressed air source to introduce air pulses required to disperse powder (45).

delivery because they trap a significant amount of aerosols. A plot of pressure drop versus gas flowrate for endotracheal tubes with different internal diameters (63) shows that narrower tubes had much sharper increase in resistance with the airflow. This implies that an increased airflow in a narrower tracheal tube causes higher increase in turbulence that consequently leads to further deagglomeration and/or enhanced aerosol depositions in the tube. Particle size of the aerosols will also determine the impaction loss in the tube. Larger particles or agglomerates are more likely to impact, resulting in lower delivered doses. The end result is the sum of these phenomena, which is very difficult to be predicted.

When a novel DPI (Figure 5) was used to disperse $5 \mathrm{mg}$ of nano-sized budesonide particles at $30 \mathrm{~L} / \mathrm{min}$, increasing the tube diameter from 5.0 to $6.5 \mathrm{~mm}$ increased the dose emitted from the endotracheal tube by $10 \%$ but remained constant when the tube was further increased to $8.0 \mathrm{~mm}$ (Figure 11) (11). The Reynolds number (turbulence indicator) for 3, 5, 6.5 and $8 \mathrm{~mm}$ is $14,067,8,440,6,492$, 5,275 , respectively. The calculated Reynolds numbers show a much higher turbulence level for $3 \mathrm{~mm}$ diameter. FPF $<3.3 \mu \mathrm{m}$ was the highest for $3.0 \mathrm{~mm}$ diameter, which indicates that turbulence in the tubing further deagglomerated the powder. When the inspiratory flow rate was decreased to $23 \mathrm{~L} / \mathrm{min}$, the trend observed was different (11). The smallest tube diameter $(3.0 \mathrm{~mm})$ still showed the highest FPF but the emitted dose was lower. This implied that the high turbulence caused both enhanced deagglomeration as well as greater powder deposition in the tubing.

Feng et al. showed that approximately $11 \%$ more drugs can be delivered using a short tracheostomy tube compared to a long endotracheal tube due to less deposition in the tube (Figure 12) (46). Tang et al. and Leung et al. found that the powder deposition inside the wider endotracheal tube was found to be similar to that of a narrower one, leading to a comparable delivered dose between the two tubes $(6,44)$. It was claimed that this was due to fine particles emitted from the Osmohaler ${ }^{\mathrm{TM}}$ that were able to follow the air stream without impaction in the tube. The FPF for the $9.0 \mathrm{~mm}$ endotracheal tube was significantly higher (20.4\%) compared to that with the $7.0 \mathrm{~mm}$ tracheostomy tube. This further validates the previous claim that the fine particles were able to follow the air stream and exit the tube.

To reduce impaction loss in the tracheal tube, it would be better to use a tube with a larger diameter when possible to reduce the turbulence level. A suitable DPI should be selected so that optimal powder deagglomeration is achieved prior to aerosol emission from the inhaler. Smaller particles will result in minimal impaction in the tube and lead to a higher dose received by patients.

\section{Potential factors affecting dry powder delivery during respiratory supports}

\section{Gas density}

The Reynolds number used to indicate turbulent and laminar regions is proportional to gas density. Heliox, a mixture of helium and oxygen, is a low-density gas used to treat obstructive pulmonary diseases $(64,65)$. Inhalation of heliox can decrease flow turbulence and further reduce airway 

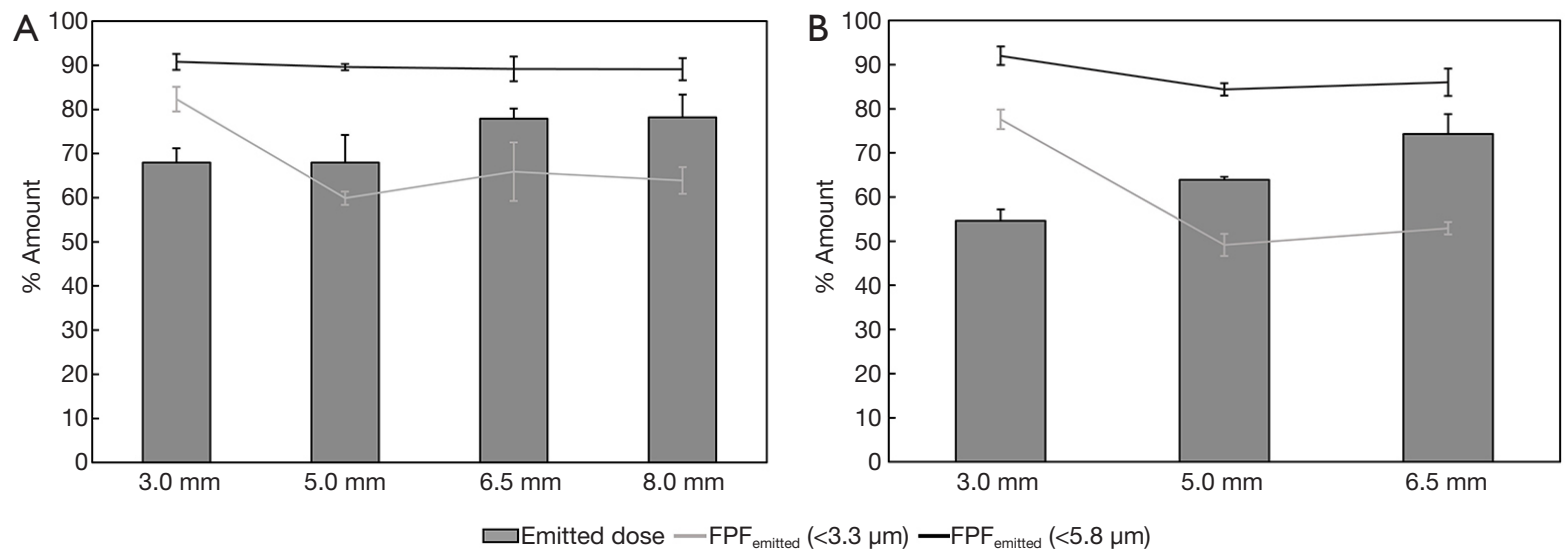

Figure 11 Effect of different internal diameter of tracheal tubes on the emitted dose of nano-sized budesonide particles dispersed by a novel DPI connected inline to a (A) mechanical ventilator at $30 \mathrm{~L} / \mathrm{min}$ and (B) ventilation bag at $23 \mathrm{~L} / \mathrm{min}$.

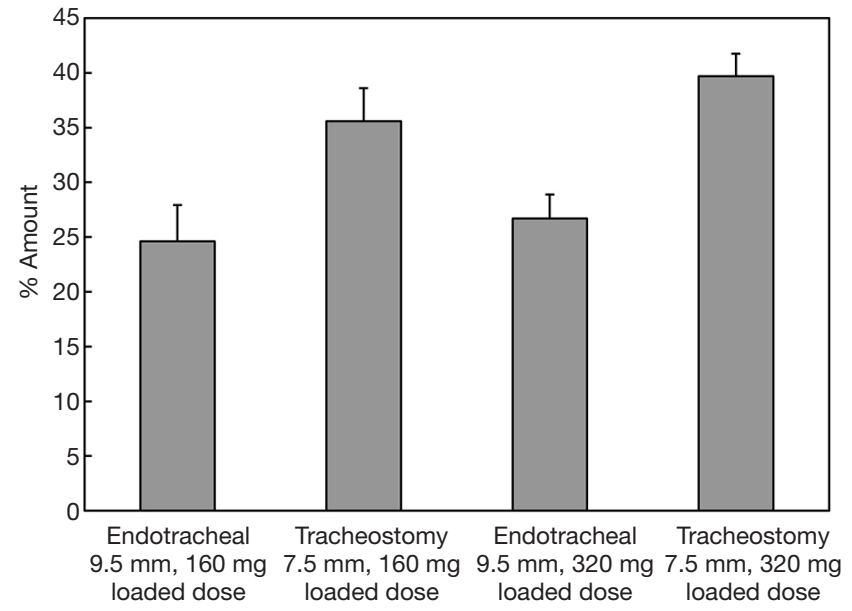

Figure 12 Effect of the internal diameter and length of tracheal tubes on the emitted dose of mannitol powder dispersed from an Osmohaler ${ }^{\mathrm{TM}}$ connected inline to a mechanical ventilator. The inspiratory airflow was $50 \mathrm{~L} / \mathrm{min}$ (46).

resistance. Moreover, lowering the flow turbulence is also conducive to the transport of aerosols during respiratory supports since aerosol performance is dependent not only on physical properties of the particles, but also those of the carrier gas (66-68). Previous studies have demonstrated that drug delivery efficiency of both pMDI and nebulizer was improved by using heliox in various respiratory supports (69-74). The performance of jet nebulizers only deteriorates when heliox is used to power the jet nebulizer. As Bernoulli's principle governs the aerosol generation mechanism in the jet nebulizers, lowering the gas density would reduce the pressure drop across a jet orifice, which further reduces aerosol production $(74,75)$.

It is uncertain whether heliox is beneficial for DPIs. Turbulence is associated with the aerosol performance of powders. Using heliox to actuate DPIs may reduce the turbulence and may not provide sufficient kinetic energy to promote disaggregation (18). Previous studies showed the fine particle fraction as a function of the deagglomeration efficiency was increased with the level of turbulence by an increase of flowrate $(17,76)$. Although the DPI dispersion may be worsened by using heliox, aerosol penetration through the ventilator circuit containing heliox may be improved. Thus, further studies are required to confirm the delivery efficiency of dry powders in the circuit of respiratory supports containing heliox.

\section{Should lactose- or mannitol-based formulation be forbidden in mechanical ventilation to prevent bacterial growth and ventilator-associated pneumonia (VAP)?}

To facilitate powder dispersion and achieve accurate metered doses, micron-sized drug particles are often blended with coarse excipient particles in DPI formulations. Lactose and mannitol are commonly used as excipients for DPI formulations as they are physiochemically stable and are compatible with many drugs. Drug particles initially attach to the excipient particles as carriers and become detached during dispersion. When delivering aerosols from a DPI during an invasive mechanical ventilation, the large excipient particles have a greater tendency to deposit in the ETT due to its small dimension contributing to strong turbulence and impaction.

The deposited excipients may serve as nutrients 
for pathogens adhering inside the ETT. Assaf et al. demonstrated that although no major difference in the growth rate of Streptococcus mutans was found with increasing lactose concentration from $0 \%$ to $5 \%$, the presence of lactose can stimulate biofilm generation (77). The phenomenon may be due to a decrease in $\mathrm{pH}$ from lactose metabolism. Moore et al. examined the effect of mannitol concentration on the growth of various respiratory pathogens, including Pseudomonas aeruginosa, Burkbolderia cenocepacia, and Stenotrophomonas maltophilia. Proliferation of all the pathogens initially increased with increasing mannitol concentration, reached maximum at $2 \%$ and $4 \%$ mannitol and then subsequently declined (78). Pathogens in the ETT can be easily aspirated and cause VAP as several mechanisms of human respiratory defense are compromised after intubation $(79,80)$. To minimize this effect, using excipient-free powder formulation may minimize pathogens' growth in the ETT. However, further research is needed to affirm if excipients deposits in the ventilator circuit and the ETT facilitate pathogenic growth.

\section{Conclusions}

DPIs can be used with a wide range of active pharmaceutical ingredients and possess several advantages for inhaled drug delivery. However, they have rarely been used during respiratory supports due to the perception that powder performance will be heavily deteriorated by humidified air. Although humidity does affect the powder dispersion and emission, the extent of influence depends on the exposure period and hygroscopicity of the formulation. During momentary exposure in the circuit of respiratory supports, the impact of humidity is likely to be limited. This myth of 'DPI can't be used on mechanical ventilators' has been dispelled recently by a number of in vitro studies. DPIs have been adapted in-line in a respiratory circuit and successfully delivered powders through humidified air. There are two approaches to adapt DPIs in the circuit. One is to enclose a commercial DPI in a delivery chamber. Another is to use a novel DPI customized to the circuit of respiratory supports. Either of these two would likely be for off-label use of the drug or drug product if it was not originally approved for administration via a mechanical ventilator. Inspiratory flowrate, as the driving force of aerosolization, must be correctly chosen to balance between maximum deagglomeration and minimum impaction loss in the line. Due to the difficulty in achieving this balance, there is an urgent need for the new generation DPIs that can deagglomerate sufficiently at low flowrate and/or use external power source for aerosolization. For the time being, the delivery chamber is an attractive method due to its simplicity, dose flexibility and cost effectiveness. The use the chamber will further help minimize any necessary modification of the commercial DPIs to avoid regulatory issues. The lung dose that can be delivered from the commercial DPIs to patients on respiratory support may be different to those who can breathe unassisted. In vitro test is of utmost important which would ideally be followed by in vivo scintigraphy studies to confirm lung deposition.

\section{Acknowledgments}

Funding: HK Chan is grateful to Mr. Richard Stenlake for his generous financial support.

\section{Footnote}

Provenance and Peer Review: This article was commissioned by the Guest Editors (Dr. James B. Fink and Dr. Zhe Luo) for the series "Medical Aerosol in Acute and Critical Care" published in Annals of Translational Medicine. The article was sent for external peer review organized by the Guest Editors and the editorial office.

Conflicts of Interest: All authors have completed the ICMJE uniform disclosure form (available at http://dx.doi. org/10.21037/atm-20-3946). The series "Medical Aerosol in Acute and Critical Care" was commissioned by the editorial office without any funding or sponsorship. The authors have no other conflicts of interest to declare.

Ethical Statement: The authors are accountable for all aspects of the work in ensuring that questions related to the accuracy or integrity of any part of the work are appropriately investigated and resolved.

Open Access Statement: This is an Open Access article distributed in accordance with the Creative Commons Attribution-NonCommercial-NoDerivs 4.0 International License (CC BY-NC-ND 4.0), which permits the noncommercial replication and distribution of the article with the strict proviso that no changes or edits are made and the original work is properly cited (including links to both the formal publication through the relevant DOI and the license). See: https://creativecommons.org/licenses/by-nc$\mathrm{nd} / 4.0 /$. 


\section{References}

1. Myers TR.. The science guiding selection of an aerosol delivery device. Respir Care 2013;58:1963-73.

2. Dal Negro RW. Dry powder inhalers and the right things to remember: A concept review. Multidiscip Resp Med 2015;10:13.

3. Clark AR, Weers JG, Dhand R. The confusing world of dry powder inhalers: It is all about inspiratory pressures, not inspiratory flow rates. J Aerosol Med Pulm Drug Deliv 2020;33:1-11.

4. Pollack CV, Fleisch KB, Dowsey K. Treatment of acute bronchospasm with $\beta$-adrenergic agonist aerosols delivered by a nasal bilevel positive airway pressure circuit. Ann Emerg Med 1995;26:552-7.

5. Rittayamai N, Katsios CM, Beloncle F, et al. Pressurecontrolled vs volume-controlled ventilation in acute respiratory failure: A physiology-based narrative and systematic review. Chest 2015;148:340-55.

6. Tang P, Chan HK, Rajbhandari D, et al. Method to introduce mannitol powder to intubated patients to improve sputum clearance. J Aerosol Med Pulm Drug Deliv 2011;24:1-9.

7. Farkas D, Hindle M, Longest PW. Development of an inline dry powder inhaler that requires low air volume. J Aerosol Med Pulm Drug Deliv 2018;31:255-65.

8. Farkas D, Hindle M, Longest PW. Application of an inline dry powder inhaler to deliver high dose pharmaceutical aerosols during low flow nasal cannula therapy. Int J Pharm 2018;546:1-9.

9. Dhand R. How Should Aerosols Be Delivered During Invasive Mechanical Ventilation? Respir Care 2017;62:1343-67.

10. Walenga RL, Longest PW, Kaviratna A, et al. Aerosol drug delivery during noninvasive positive pressure ventilation: Effects of intersubject variability and excipient enhanced growth. J Aerosol Med Pulm Drug Deliv 2017;30:190-205.

11. Pornputtapitak W, El-Gendy N, Mermis J, et al. NanoCluster budesonide formulations enable efficient drug delivery driven by mechanical ventilation. Int J Pharm 2014;462:19-28.

12. Okuda T, Tang P, Yu J, et al. Powder aerosol delivery through nasal high-flow system: In vitro feasibility and influence of process conditions. Int J Pharm 2017;533:187-97.

13. Yang MY, Chan JGY, Chan HK. Pulmonary drug delivery by powder aerosols. J Control Release 2014;193:228-40.

14. Pilcer G, Wauthoz N, Amighi K. Lactose characteristics and the generation of the aerosol. Adv Drug Deliv Rev 2012;64:233-56.

15. Shur J, Harris H, Jones MD, et al. The role of fines in the modification of the fluidization and dispersion mechanism within dry powder inhaler formulations. Pharm Res 2008;25:1631-40.

16. Hoppentocht M, Hagedoorn P, Frijlink HW, et al. Technological and practical challenges of dry powder inhalers and formulations. Adv Drug Deliv Rev 2014;75:18-31.

17. Coates MS, Chan HK, Fletcher DF, et al. Effect of design on the performance of a dry powder inhaler using computational fluid dynamics. Part 2: Air inlet size. J Pharm Sci 2006;95:1382-92.

18. Gac J, Sosnowski TR, Gradoń L. Turbulent flow energy for aerosolization of powder particles. J Aerosol Sci 2008;39:113-26.

19. Castellanos A. The relationship between attractive interparticle forces and bulk behaviour in dry and uncharged fine powders. Adv Phys 2005;54:263.

20. Weers JG, Miller DP. Formulation design of dry powders for inhalation. J Pharm Sci 2015;104:3259-88.

21. de Boer AH, Hagedoorn P, Hoppentocht M, et al. Dry powder inhalation: past, present and future. Expert Opin Drug Deliv 2017;14:499-512.

22. Chow AHL, Tong HHY, Chattopadhyay P, et al. Particle engineering for pulmonary drug delivery. Pharm Res 2007;24:411-37.

23. Jashnani RN, Byron PR, Dalby RN. Testing of dry powder aerosol formulations in different environmental conditions. Int J Pharm 1995;113:123-30.

24. Kwok PCL, Chan H-K. Effect of relative humidity on the electrostatic charge properties of dry powder inhaler aerosols. Pharm Res 2008;25:277-88.

25. Yu J, Wong J, Ukkonen A, et al. Effect of relative humidity on bipolar electrostatic charge profiles of dry powder aerosols. Pharm Res 2017;34:1707-15.

26. Zhu K, Tan RBH, Kiong Ng W, et al. Analysis of the influence of relative humidity on the moisture sorption of particles and the aerosolization process in a dry powder inhaler. J Aerosol Sci 2008;39:510-24.

27. Davidson N, Tong HJ, Kalberer M, et al. Measurement of the Raman spectra and hygroscopicity of four pharmaceutical aerosols as they travel from pressurised metered dose inhalers (pMDI) to a model lung. Int J Pharm 2017;520:59-69.

28. Yu J, Chan HK, Gengenbach T, et al. Protection of hydrophobic amino acids against moisture-induced 
deterioration in the aerosolization performance of highly hygroscopic spray-dried powders. Eur J Pharm Biopharm 2017;119:224-34.

29. Yu J, Romeo MC, Cavallaro A, et al. Protective effect of sodium stearate on the moisture-induced deterioration of hygroscopic spray-dried powders. Int J Pharm 2018;541:11-8.

30. Wong FJ, Dudney T, Dhand R. Aerosolized antibiotics for treatment of pneumonia in mechanically ventilated subjects. Respir Care 2019;64:962-79.

31. Zampieri FG, Nassar AP Jr, Gusmao-Flores D, et al. Nebulized antibiotics for ventilator-associated pneumonia: a systematic review and meta-analysis. Crit Care 2015;19:150.

32. Ari A, Fink JB. Guidelines for aerosol devices in infants, children and adults: which to choose, why and how to achieve effective aerosol therapy. Expert Rev Respir Med 2011;5:561-72.

33. Dolovich MB, Ahrens RC, Hess DR, et al. Device selection and outcomes of aerosol therapy: Evidencebased guidelines: American college of chest physicians/ american college of asthma, allergy, and immunology. Chest 2005;127:335-71.

34. Parumasivam T, Leung SSY, Tang P, et al. The delivery of high-dose dry powder antibiotics by a low-cost generic inhaler. AAPS J 2017;19:191-202.

35. Schuster A, Haliburn C, Döring G, et al. Safety, efficacy and convenience of colistimethate sodium dry powder for inhalation (Colobreathe DPI) in patients with cystic fibrosis: a randomised study. Thorax 2013;68:344-50.

36. Chan JGY, Chan H-K, Prestidge CA, et al. A novel dry powder inhalable formulation incorporating three firstline anti-tubercular antibiotics. Eur J Pharm Biopharm 2013;83:285-92.

37. Chan JGY, Duke CC, Ong HX, et al. A novel inhalable form of rifapentine. J Pharm Sci 2014;103:1411-21.

38. Khatib I, Tang P, Ruan J, et al. Formation of ciprofloxacin nanocrystals within liposomes by spray drying for controlled release via inhalation. Int J Pharm 2020;578:119045.

39. Ari A, Areabi H, Fink JB. Evaluation of aerosol generator devices at 3 locations in humidified and non-humidified circuits during adult mechanical ventilation. Respir Care 2010;5 5:837-44.

40. Dhand R, Tobin M. Bronchodilator delivery with metered-dose inhalers in mechanically-ventilated patients. Eur Respir J 1996;9:585-95.

41. Ke WR, Wang WJ, Lin TH, et al. In vitro evaluation of aerosol performance and delivery efficiency during mechanical ventilation between soft mist inhaler and pressurized metered-dose inhaler. Respir Care 2020;65:1001-10.

42. Anand NK, McFarland AR, Kihm KD, et al. Optimization of aerosol penetration through transport lines. Aerosol Sci Technol 1992;16:105-12.

43. Everard ML, Devadason SG, Le Souëf PN. In vitro assessment of drug delivery through an endotracheal tube using a dry powder inhaler delivery system. Thorax 1996;51:75-7.

44. Leung SSY, Parumasivam T, Tang P, et al. A proof-ofprinciple setup for delivery of Relenza ${ }^{\circledR}$ (Zanamivir) inhalation powder to intubated patients. J Aerosol Med Pulm Drug Deliv 2016;29:30-5.

45. Pohlmann G, Iwatschenko P, Koch W, et al. A novel continuous powder aerosolizer (CPA) for inhalative administration of highly concentrated recombinant surfactant protein-C (rSP-C) surfactant to preterm neonates. J Aerosol Med Pulm Drug Deliv 2013;26:370-9.

46. Feng B, Tang P, Leung S, et al. A novel in-line delivery system to administer dry powder mannitol to mechanically ventilated patients. J Aerosol Med Pulm Drug Deliv 2017;30:100-7.

47. Wallin M, Tang P, Chang RYK, et al. Aerosol drug delivery to the lungs during nasal high flow therapy: An in vitro study. BMC Pulm Med 2019;19:42.

48. Nseir S, Ader F, Lubret R, et al. Pathophysiology of airway colonization in critically ill COPD patient. Curr Drug Targets 2011;12:514-20.

49. Nseir S, Zerimech F, Jaillette E, et al. Microaspiration in intubated critically ill patients: Diagnosis and prevention. Infect Disord Drug Targets 2011;11:413-23.

50. Guillon A, Vecellio L, Monte M. Pulmonary delivery of dry powders during invasive mechanical ventilation: Innovations are required. J Aerosol Med Pulm Drug Deliv 2016;29:215-6.

51. Tonnelier A, Lellouche F, Bouchard P-A, et al. Impact of humidification and nebulization during expiratory limb protection: An experimental bench study. Respir Care 2013;58:1315-22.

52. Kiatboonsri S, Kiatboonsri C, Theerawit P. Fatal respiratory events caused by zanamivir nebulization. Clin Infect Dis 2010;50:620.

53. Ryan SN, Rankin N, Meyer E, et al. Energy balance in the intubated human airway is an indicator of optimal gas conditioning. Crit Care Med 2002;30:355-61.

54. Young PM, Price R, Tobyn MJ, et al. The influence 
of relative humidity on the cohesion properties of micronized drugs used in inhalation therapy. J Pharm Sci 2004;93:753-61.

55. Behara SRB, Longest PW, Farkas DR, et al. Development of high efficiency ventilation bag actuated dry powder inhalers. Int J Pharm 2014;465:52-62.

56. Longest PW, Tian G. Development of a new technique for the efficient delivery of aerosolized medications to infants on mechanical ventilation. Pharm Res 2015;32:321-36.

57. Wittich CM, Burkle CM, Lanier WL. Ten common questions (and their answers) about off-label drug use. Mayo Clin Proc 2012;87:982-90.

58. Gazarian M, Kelly M, McPhee JR, et al. Off-label use of medicines: consensus recommendations for evaluating appropriateness. Med J Aust 2006;185:544-8.

59. Crowder TM. Vibration technology for active dry-powder inhalers. Available online: https://pdfs.semanticscholar.org /5285/3c4a2bc106137901efaae989b4ba8f5187c4.pdf

60. Corcoran TE, Venkataramanan R, Hoffman RM, et al. Systemic delivery of atropine sulfate by the MicroDose Dry-Powder Inhaler. J Aerosol Med Pulm Drug Deliv 2013;26:46-55.

61. Schmalisch G, Wilitzki S, Wauer RR. Differences in tidal breathing between infants with chronic lung diseases and healthy controls. BMC Pediatr 2005;5:36.

62. Guérin C, Fassier T, Bayle F, et al. Inhaled bronchodilator administration during mechanical ventilation: How to optimize it, and for which clinical benefit? J Aerosol Med Pulm Drug Deliv 2008;21:85-96.

63. Dhand R. Special problems in aerosol delivery: artificial airways. Respir Care 2000;45:636-45.

64. Hashemian SM, Fallahian F. The use of heliox in critical care. Int J Crit Illn Inj Sci 2014;4:138-42.

65. Rodrigo G, Pollack C, Rodrigo C, et al. Heliox for nonintubated acute asthma patients. Cochrane Database Syst Rev 2006;(4):CD002884.

66. Peterson JB, Prisk GK, Darquenne C. Aerosol deposition in the human lung periphery is increased by reduceddensity gas breathing. J Aerosol Med Pulm Drug Deliv 2008;21:159-68.

67. Corcoran TE, Gamard S. Development of aerosol drug delivery with helium oxygen gas mixtures. J Aerosol Med 2004;17:299-309.

68. Gemci T, Shortall B, Allen GM, et al. A CFD study of the throat during aerosol drug delivery using heliox and air. J Aerosol Sci 2003;34:1175-92.

69. Ari A, Harwood R, Sheard M, et al. In vitro comparison of heliox and oxygen in aerosol delivery using pediatric high flow nasal cannula. Pediatr Pulmonol 2011;46:795-801.

70. Dailey PA, Harwood R, Walsh K, et al. Aerosol delivery through adult high flow nasal cannula with heliox and oxygen. Respir Care 2017;62:1186-92.

71. Garner SS, Wiest DB, Stevens CE, et al. Effect of heliox on albuterol delivery by metered-dose inhaler in pediatric in vitro models of mechanical ventilation. Pharmacotherapy 2006;26:1396-402.

72. Corcoran T, Shortall B, Kim I, et al. Aerosol drug delivery using heliox and nebulizer reservoirs: Results from an MRI-based pediatric model. J Aerosol Med 2003;16:263-71.

73. O'Callaghan C, White J, Jackson J, et al. The effects of Heliox on the output and particle-size distribution of salbutamol using jet and vibrating mesh nebulizers. J Aerosol Med 2007;20:434-44.

74. Goode ML, Fink JB, Dhand R, et al. Improvement in aerosol delivery with helium-oxygen mixtures during mechanical ventilation. Am J Respir Crit Care Med 2001;163:109-14.

75. Hess DR, Acosta FL, Ritz RH, et al. The effect of heliox on nebulizer function using a $\beta 2$-agonist bronchodilator. Chest 1999;115:184-9.

76. Voss A, Finlay WH. Deagglomeration of dry powder pharmaceutical aerosols. Int J Pharm 2002;248:39-50.

77. Assaf D, Steinberg D, Shemesh M. Lactose triggers biofilm formation by Streptococcus mutans. Int Dairy J 2015;42:51-7.

78. Moore JE, Rendall JC, Downey DG. Pseudomonas aeruginosa displays an altered phenotype in vitro when grown in the presence of mannitol. Br J Biomed Sci 2015;72:115-9.

79. Pneumatikos Ioannis A, Dragoumanis Christos K, Bouros Demosthenes E. Ventilator-associated pneumonia or endotracheal tube-associated pneumonia? An approach to the pathogenesis and preventive strategies emphasizing the importance of endotracheal tube. Anesthesiology 2009;110:673-80.

80. Gil-Perotin S, Ramirez P, Marti V, et al. Implications of endotracheal tube biofilm in ventilator-associated pneumonia response: a state of concept. Crit Care 2012;16:R93.

Cite this article as: Ke WR, Chang RYK, Kwok PCL, Tang P, Chen L, Chen D, Chan HK. Administration of dry powders during respiratory supports. Ann Transl Med 2021;9(7):596. doi: 10.21037/atm-20-3946 